\title{
The efficacy of Clorhexidine $0.2 \%$ after scaling in marginal gingivitis
}

\author{
M Shahrohisham* and Widowati Witjaksono** \\ * Student of School of Dental Sciences University Science Malaysia \\ ** Department of Periodontic, School of Dental Sciences University \\ Science Malaysia and Faculty of Dentistry Airlangga University
}

\begin{abstract}
Thirty male subjects aged around 20-30 years old, with complete anterior teeth, no inter proximal caries and good general health conditions were selected by using simple random sampling. The anterior teeth were divided into 2 segments right side for 11, 12, 13 and left side for 21, 22, and 23. These two sites were treated by different way for comparing two treatment variables, between scaling therapy alone and scaling therapy with adjunction of Chlorhexidine (CHX) 0.2\%. Gingival Index (GI) score was used to determine the gingivitis status of the subjects. Clinical experiment showed that the duration of healing process in subjects treated with scaling with adjunction of CHX $0.2 \%$ was faster than scaling therapy alone group. However, in the statistical analysis, there was no significant difference because of several factors. In conclusion, it was found that CHX $0.2 \%$ had the efficacy to enhance the healing process in the marginal gingivitis patient that was treated by scaling therapy, but further study using CHX $0.2 \%$ with longer duration time should be done to achieve more pronounce effect
\end{abstract}

Key words: chlorhexidine, marginal gingivitis, chemical plaque control agent

Correspondence: Widowati, Department of Periodontic, School of Dental Sciences University Science Malaysia, Health Campus 16150 K. Kerian, Malaysia.

\section{INTRODUCTION}

Gingivitis is inflammation of the gingiva in the absence of clinical attachment loss. ${ }^{1}$ It is a reversible disease. ${ }^{2}$ This disease was sub-classified based upon etiology, clinical presentation and associated complicating factors. Marginal gingivitis is one of the classifications of gingivitis. It is gingivitis involve the gingival margin and may include a portion of the contiguous attached gingiva. ${ }^{3,4}$ It occur widely in most populations affecting both children and adult. Adolescents have a higher prevalence of gingivitis than pre-pubertal children or adult due to increase in sex hormone during pubertal effects and the composition of the sub gingival micro flora. The most common form of gingivitis is plaque associated gingivitis in which a buildup of bacteria plaque irritates the gingiva, resulting in redness, swelling and pain. ${ }^{2}$

There is study found that many patients lack the motivation or skills to attain and maintain a plaque free state for significant period time. ${ }^{2}$ Many patient with gingivitis have calculus and the ability to remove bacterial plaque, an acceptable therapeutic result for these individuals is usually obtained when personal plaque control measures are performed in conjunction with professional removal of plaque, calculus and other local factors. Scaling and root planning procedures are using hand or ultrasonic instruments accomplish removal of dental calculus. These procedures are to remove plaque and calculus to reduce the number of oral bacteria below the threshold level capable of initiating inflammation. ${ }^{5}$
The use of chemical plaque control agents to assist in the reduction of bacterial plaque was beneficial for the prevention and treatment of gingivitis in some patients. If properly used, the addition of chemical plaque control agents to a gingivitis treatment methode for patient with deficient plaque control will likely results in reduction of gingivitis. One of the agents is CHX. It has been test extensively and has been shown to be the most effective chemical plaque control and the most available agent. There was study found that $\mathrm{CHX}$ containing rinses to be more effective then phenolic and plant alkaloid rinses. ${ }^{6}$ The efficacy of $\mathrm{CHX}$ as an anti-plaque agent is dose dependent in the range of $0.03 \%$ to $0.2 \% \mathrm{CHX}$ and is an active agent against a wide range of gram-positive and gram-negative microorganisms and fungi by altered the bacteria cell wall. ${ }^{6}$ The aim of this study is to evaluate the efficacy of using CHX $0.2 \%$ after scaling therapy in marginal gingivitis.

\section{MATERIALS AND METHOD}

Patients seeking at Dental Clinic Hospital University Sains Malaysia (HUSM) were selected and invited to participate in this study. Only male volunteers aged around 20 to 30 years old with complete anterior teeth and no inter proximal caries were taken. Those with systemic disease and not taken standard oral hygiene instruction were excluded. Women were excluded because they tend to more hormonal imbalance, which affect the result of this study. Informed consent was obtained from all volunteers. 
A clinical experiment study design was used for data collection. The gingivitis status per visit was recorded. Gingivitis status was determined by using Gingival Index (GI) from Loe and Silnes 1967.7 The anterior teeth were divided into 2 segments, right side for 11, 12, 13 and left side for $21,22,23$. After whole mouth scaling and prophylaxis were done, the right side was applied by CHX $0.2 \%$ two times per day in the morning and night by using cotton pellets starting on the same day, while the other side without the adjunction of $\mathrm{CHX} 0.2 \%$. They should continue applying CHX $0.2 \%$ everyday during the observation time. Every patient had to attend the appointment on $1^{\text {st }}, 3^{\text {rd }}, 5^{\text {th }}$ and $7^{\text {th }}$ day to re-evaluate. Independent t-test was used to analyze the data.

\section{RESULTS}

The reduction of gingival inflammation after scaling therapy could be interpreted in the table 1 as follows: day 0 (before treatment) mean score was 1.50 (moderate gingivitis), mean score on $1^{\text {st }}$ day (after therapy) was 1.40 , $3^{\text {rd }}$ day was $1.20,5^{\text {th }}$ day was 1.00 and $7^{\text {th }}$ day was 0.80 (mild gingivitis).

As for the reduction of gingival inflammation after scaling therapy followed by CHX $0.2 \%$ application could be interpreted as follows: before treatment (day 0) mean score was 1.83 (moderate gingivitis), mean score on $1^{\text {st }}$ day (after therapy) was $1.29,3^{\text {rd }}$ day was $0.91,5^{\text {th }}$ day was 0.67 and $7^{\text {th }}$ day was 0.41 (mild gingivitis). These results showed that there were reduction in the severity of gingivitis from moderate to mild gingivitis both in patient that was treated by scaling therapy alone and scaling followed by CHX $0.2 \%$ application. This table also showed that all $\mathrm{p}$ values were less than 0.05 , which means there was a significant decrease of GI scores by both therapies. In detail, the efficacy of both therapies can be seen from the figure 1. The differences between scaling therapy alone and scaling therapy with followed by $\mathrm{CHX} 0.2 \%$ application can be seen in table 2 .

The reduction of inflammation was obvious seen on the $1^{\text {st }}, 3^{\text {rd }}, 5^{\text {th }}$ and $7^{\text {th }}$ days which show that the mean GI score of scaling therapy with followed by $\mathrm{CHX} 0.2 \%$ was smaller than the mean in the scaling therapy alone.

However, on the other hand, both therapies had $\mathrm{p}$ value more than 0.05 , which means, there were no significant different in healing process between scaling therapy alone and scaling by adjunction of CHX $0.2 \%$.

\section{DISCUSSION}

In this study, observations were done on the $1^{\text {st }}$ day, $3^{\text {rd }}$ day, $5^{\text {th }}$ day, and $7^{\text {th }}$ day or sevent day. The first day $\left(1^{\text {st }}\right.$ day) examinations were to observe the CHX $0.2 \%$ effect in the scaling therapy, while the rest of the days ( $3^{\text {rd }}$ day, $5^{\text {th }}$ day and $7^{\text {th }}$ day) were to examine the whole healing process. This statement was supported by one study which was stated that the healing process occurs in $7^{\text {th }}-10^{\text {th }}$ days. ${ }^{8}$

From the result study and statistical analysis, it showed that with scaling therapy, the GI score was reduce, which was also mentioned ${ }^{5}$ According to them, scaling and root planning can reduce the severity of gingivitis and pocket formation. Besides that, frequent scaling could increase the duration of healing. 9

Antiseptic mouth wash usage can prevent plaque formation, which contained of microorganisms, which can cause caries formation and periodontal diseases, like gingivitis. This study also showed decrease in GI score in sample who was treated by scaling therapy with $\mathrm{CHX} .{ }^{10}$

From this clinical investigation it was found that the duration of healing process in the samples that were treated by scaling with adjunction of CHX $0.2 \%$ is faster than scaling therapy alone group. However, in statistical analysis there was no significant different, may be because of several factors such as patients were not compliance to $\mathrm{CHX}$, wrong technique during application of the agent and short duration of observation.

The conclusion it was found that CHX $0.2 \%$ has the efficacy to enhance the healing process in marginal gingivitis patient that was scaling, however further study about using CHX $0.2 \%$ agent with longer duration time should be done to achieve more pronounce result.

Table 1. Gingival Index (GI) score in healing process of gingivitis after therapy

\begin{tabular}{|c|c|c|c|c|c|}
\hline Therapy Day & 0 & $1^{\text {st }}$ & $3^{\text {rd }}$ & $5^{\text {th }}$ & $7^{\text {th }}$ \\
\hline \multirow{4}{*}{$\begin{array}{l}\text { Scaling } \\
\mathrm{P} \text { value }\end{array}$} & Mean (SD) & Mean (SD) & Mean (SD) & Mean (SD) & Mean (SD) \\
\hline & $1.50(0.39)$ & $1.40(0.40)$ & $1.20(0.41)$ & $1.00(0.35)$ & $0.80(0.32)$ \\
\hline & & 0.03 & & & \\
\hline & & & 0.01 & 0.01 & \\
\hline \multirow{2}{*}{$\begin{array}{l}\text { Scaling + CHX } 0.2 \% \\
\text { P value }\end{array}$} & $1.83(1.78)$ & $1.29(0.39)$ & $0.91(0.39)$ & $0.67(0.30)$ & $\begin{array}{c}0.01 \\
0.41(0.23)\end{array}$ \\
\hline & & & 0.03 & 0.03 & 0.03 \\
\hline
\end{tabular}

Independent t-test 
Table 1. Gingival Index (GI) score in healing process of gingivitis after therapy

\begin{tabular}{|c|c|c|c|c|}
\hline Therapy Day & 0 & $1^{\mathrm{st}}$ & $5^{\mathrm{th}}$ & $7^{\text {th }}$ \\
\hline & Mean (SD) & Mean (SD) & Mean (SD) & Mean (SD) \\
\hline Scaling & $1.50(0.39)$ & $1.40(0.40)$ & $1.00(0.35)$ & $0.80(0.32)$ \\
\hline Scaling + CHX $0.2 \%$ & $1.83(1.78)$ & $1.29(0.39)$ & $0.67(0.30)$ & $0.41(0.23)$ \\
\hline$P$ value & 0.27 & 0.55 & 0.23 & 0.09 \\
\hline
\end{tabular}

Paired t-test

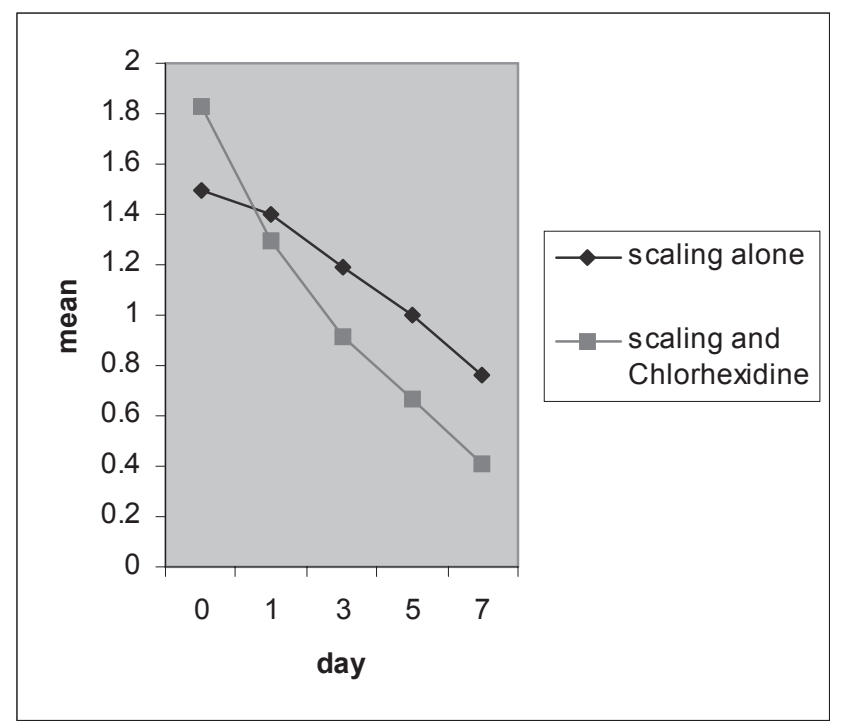

Figure 1. Gingival index after therapies.

\section{REFERENCES}

1. The American Academy of Periodontology. Plaque induced gingivitis. J Peridontol 2000 May; 71(Suplement):851-52. Available from URL: http:www//perio.org/resources-products/posppr3-2.html.

2. Lindhe J. Clinical periodontology and implant dentistry. $4^{\text {th }}$ ed. In: Karring T, Niklaus P, Lang, editors. Oxford: Blackwell Publishing Co; 2003. p. 200-3.

3. James Stephen MD. Gingivitis. e Medicine. Available from: URL: http://www.emedicine.com/emerg/topic 217.htm. Accessed December 20, 2004.

4. Gary C. Armitage. Development of a classification system for periodontal diseases and conditions. Ann Periodontol 1999 December; 4(1):1-5.

5. Martu S, Mocanu C, Popovici CG. Comparison on the effects of chlorhexidine in subgingival applocation in the treatment of adult periodontitis. Rev Med Chir Soc Med Nat lasi. 2000 Apr-June; 104(2):125-30.

6. Jacob Horwitz, Eli E, Machtei, Micha Peled, Dov Laufer. Amine fluoride/stannous fluoride and chlorhexidine mouthwashes as adjuncts to surgical periodontal therapy: A comparative study. J of Periodontol 2000 Oct; 71(10):1601-6.

7. Newman, Takei, Carranza. Carranza's clinical periodontology. $9^{\text {th }}$ ed. Philadelphia USA: WB Saunders Co; 2002. p. 80.

8. Haffajee AD, Socransky SS, Goodson GM. Subgingival temperature (I) relation to baseline clinical parameters. J Clin Periodontology 1992; (19):401-8.

9. Esther M Wilkins. Clinical practice of the dental hygienist. $9^{\text {th }}$ ed. A Wolters Kluwer Co. 2005. p. 647-50.

10. Pai MR, Acharya LD, Udupa N. The effect of two different dental gels and a mouthwash on plaque and gingival scores: a six-week clinical study. Int Dent J 2004 Aug; 54(4):219-23. 